\title{
Inhaltsverzeichnis
}

\section{Zur Formenlehre}

\section{Das Hauptwort}

Starke und schwache Beugung . . . . . . . I

Frieden oder Friede? Namen oder Name? . . . . . 2

Des Volkes, dem Volke - oder des Volks, dem Volk? 3

Des Rhein oder des Rheins? . . . . . . . . . 4

Des Roten Kreuz oder des Roten Kreuzes? . . . . . 6

Franz' oder Franzens? Goethe's oder Goethes? . . . 9

Friedrich des Großen oder Friedrichs des Großen? . 12

Kaiser Rotbarts . . . . . . . . . . . I3

Leopolds von Ranke oder Leopold von Rankes? . . . I4

Bögen oder Bogen? . . . . . . . . . . . . I6

Generäle oder Generale? . . . . . . . . . I6

Mann, Männer und Leute . . . . . . . . . 17

Die Stiefeln oder die Stiefel? . . . . . . . . 18

Worte oder Wörter? . . . . . . . . . . 19

Das s der Mehrzahl . . . . . . . . . . . 2I

Fünf Pfennig oder fünf Pfennige? Fünf Blätter und fünf Blatt . . . . . . . . . . 22

Schwankendes Geschlecht . . . . . . . 24

\section{Das Eigenschaftswort}

Jeden Zwanges oder jedes Zwanges? . . . . . . . 26

Mit erhobenem rechten oder rechtem Arm? . . . . 28

Sämtlicher deutscher oder sämtlicher deutschen Stämme? . . . . . . . . . . . 29

Ein schönes Åußeres oder Äußere? Großer Gelehrter oder Gelehrten? . . . . . . . . 30

Das Deutsche und das Deutsch . . . . . . . . 32

Wir Deutsche oder wir Deutschen? . . . . . 33

Nach Meldungen Dresdner Zeitungen . . . . . 33

Steigerung der Eigenschaftswörter ....... 35 


\section{Das Fürwort}

Gedenket unsrer oder gedenket unser? . . . . . 35

Derer und deren . . . . . . . . . . 36

Man und jemand . . . . . . . . . . . 37

Mit niemand anders .......... 38

Das Zahlwort ..... 39

Das Zeitwort

Vertauschte und schwankende Zeitwörter .... . 4I

Falsche Befehlsform ........... 43

Ubergeführt und überführt. Ich anerkenne? . . . . 44

Das überlegte Gefängnis . . . . . . . . . 46

Ich bin gestanden oder ich habe gestanden? . . . . 47

Singen gehört und Singen hören . . . . . . 48

Begänne oder begönne? Stände oder stünde? . . . . 49

\section{Zur Wortbildungslehre}

Ärztin und Blockleiterin . . . . . . . . . 5r

Hingebung und Hingabe ......... 52

Bremener oder Bremer? . . . . . . . . . . 55

Hallenser und Weimaraner .......... 55

Kölner Dom und Kölnische Zeitung . . . . . . 56

Hallesches oder Hallisches Tor? . . . . . . . 58

-ig, -lich, vierwöchig, zugänglich . . . . . . . 59:

Schwerwiegender oder schwerer wiegend? . . . . $6 \mathrm{r}$

Größtmöglichst ............. 62

Mißbrauch der Meiststufe . . . . . . . 63

\section{Zusammengesetzte Hauptwörter}

Das Binde-s ............. $6_{4}$

Tintefaß oder Tintenfaß? .......... 66

Apfelwein oder Apfelwein? ........... 68

Speisekarte oder Speisenkarte? . . . . . . . . 69

\section{Zur Satzlehre}

Unterdrückung des Satzgegenstandes . . . . 7I 
Die Satzaussage

Die Ausstattung war eine glänzende . . . . . . 72

Eine Menge war oder waren? . . . . . . . 75

Noch eine Mehrzahl in der Satzaussage . . . . . 76

Die Anrede . . . . . . . . . . . . 77

Die Leideform . . . . . . . . . 78

Die Mitglieder sind gebeten? . . . . . . 80

Die rückbezüglichen Zeitwörter ........ 80

Mißbrauch der Vergangenheit . . . . . . 8

Der Kampf um das Worden . . . . . . . . 85

Erzählung und Inhaltsangabe ........ 87

Zeitungsüberschriften .......... 88

Zeitenverirrung bei der Nennform ....... 9I

Nebensätze

Bezügliche Nebensätze. Welcher, welche, welches . . 92

Das und was . . . . . . . . . 95

Familie "wo" . . . . . . . . . . . . 97

Welch letzterer . . . . . . . . . . . 98

Einer der schwierigsten, der oder die? . . . . . I00

Falsch fortgesetzte Relativsätze . . . . . . . . ror

Relativsatz statt eines Hauptsatzes . . . . . . I03

Allerlei Bindewörter ............ I05

Unterdrückung des Hilfszeitworts . . . . . . . 107

Die Aussageweisen

Wirklichkeits- und Möglichkeitsform . . . . . I Io

Die Möglichkeitsform in der abhängigen Rede . . . II5

Die sogenannte Zeitenfolge (consecutio temporum) , II6

Die unkenntliche Möglichkeitsform . . . . . . . II7

Die Form der Nichtwirklichkeit . . . . . . 120

Vergleichssätze. Als wenn, als ob . . . . . . . 122

Würde .............. I23

..wolle zu den Akten . . . . . . . . . 126

Nennform und Mittelwort

Die Nennform mit um zu . . . . . . . . . 127

Das falsche $\mathrm{zu}$............ . . 132

Das Mittelwort. Gefolgt von einem Sturm SA . . . 132

Mittelwort statt eines Neben- oder Hauptsatzes . . . 136

Falsch angeschlossenes Mittelwort. . . . . . . 138 
Die Beifügungen

In Ergänzung . . . . . . . . . . . . . . I40

Die Beifügung . . . . . . . . . . . . . ${ }^{143}$

Straßennamen .............. . 144

Fachliche Bildung oder Fachbildung? schulisch . . . 146

Die Goethemutter . . . . . . . . . . . . I50

Schulze-Naumburg und Frankfurt-Oder . . . . . . I52

Magistrat Berlin . . . . . . . . . . 153

Ex libris . . . . . . . . . . . 156

Die Familie Nachfolger . . . . . . . . . . . 157

Weitere Mängel bei Geschäftsaufschriften . . . . . I59

Der grobe Unfugparagraph und das Übersetzungsrecht in fremde Sprachen . . . . . . . . . $\mathrm{I}_{22}$

Der glasweise Preis . . . . . . . . . . . . I64

Der Beisatz . . . . . . . . . . . . . $\mathrm{I} 66$

Als bei der Satzaussage . . . . . . . . . ${ }^{168}$

Titel .............. . . . . I69

Der Doktor-Ingenieur . . . . . . . . . I7I

Bindestriche ........... I72

Fürwörter

Der erstere und der letztere . . . . . . . . . I75

Derselbe, dieselbe, dasselbe . . . . . . . . ${ }^{177}$

Darin, daraus, daran; ohne es . . . . . . . . 183

Derjenige, diejenige, dasjenige . . . . . . . ${ }_{1} 86$

Jener, jene, jenes ........... 188

Zur Fall-Lehre

Zeitwörter mit unsicherem Fall . . . . . . . . . 188

Er hat mir oder mich auf den Fuß getreten? . . . . I9I

Sich an etwas halten .......... . 193

Zur Steuerung des Notstandes . . . . . . . . . 193

Zahlwörter ...... I96

Verhältniswörter

Dank und trotz . . . . . . . . . . . . 197

Anstatt und außer . . . . . . . . . . r r 199

Nördlich, südlich, vorwärts . . . . . . . . 199 
Werdende Verhältniswörter: ungerechnet, unbeschadet, bis . . . . . . . . . . 201

Ab 5. September gesperrt . . . . . . . . 203

Nach Schule und bei Vater . . . . . . . . . 204

Im oder in dem? zum oder zu dem? . . . . . . . 205

Aus „Die Grenzboten“ . . . . . . . . . . . . . 208

Wegen Unfug ............ 210

\section{Zeitbestimmungen}

Donnerstag und donnerstags - nachmittag und nachmittags ............. 2ro

Das Datum . . . . . . . . . . . . 2II

Aller vier Wochen? . . . . . . . . . . . . 212

Vorsicht bei "während“" . . . . . . . 213

Bindewort und Geschlechtswort

Und ................... 215

Als, wie, denn beim Vergleich . . . . . . 218

Die Verneinungen ... . . . . . . . 220

Warnen, daß nicht . . . . . . . . . . . 223

Der Schwund des Geschlechtswortes . . . . . . 224

Ihr oder Ihre Fräulein Tochter? . . . . . . 225

\section{Stilmängel und Stilregeln}

Mißhandelte Redensarten . . . . . . . . . 227

Vertauschung des Hauptworts und des Fürworts . . 232

Die fehlerhafte Zusammenziehung . . . . . . 234

Doppel und Ǔberfluß . . . . . . . . . . . . 237

Die Bildervermengung ......... . 24I

Vermengen zweier Fügungen ......... 244

\section{Zur Wortstellung}

Die alte gute Zeit oder die gute alte Zeit? . . . . . . 246

Die Umstellung nach ,und“ . . . . . . . . . . . 247

Die Stellung der persönlichen Fürwörter . . . . . . 249

Zwei Verhältniswörter nebeneinander . . . . . . . 252

Noch ein paar Stilregeln . . . . . . . . . . 254

Schlechter Satzbau . . . . . . . . . . 26r

Ein paar Winke zur Zeichensetzung . . . . . 265 


\section{Zu Wortschatz und Wortbedeutung}

Verwechselte Wörter . . . . . . . . 271

Der gleiche oder derselbe? . . . . . . . . . 275

Der Dritte und der andre . . . . . . . . . 276

Verwechslung von Verhältniswörtern . . . . . . 277

Fort oder weg? . . . . . . . . . . . 281

Hin und her; hoch und oben . . . . . . . . . 282

$\mathrm{Ge}$, be, ver, ent, er . . . . . . . 2885

Neue Wörter .......... . . 289

Modewörter . . . . . . . . . . . . 297

Der Gesichtspunkt und der Standpunkt . . . . . 318

Das Können und das Fühlen . . . . . . . . . 321

Das Sicheinleben . . . . . . . . . . 322

Bedingen .............. . . 323

Fertigstellen und klarlegen . . . . . . . . . 326

In etwa . . . . . . . . . . . . 328

Schwulst . . . . . . . . . . . 329

Einflußnahme und Verzichtleistung . . . . . . . 332

Die Sehnsüchte ........... . 333

Anders, andersartig und anders geartet . . . . . 334

Aufblähung des Zeitworts . . . . . . . . 335

„Die Mutter “, erschrak Lotte . . . . . . . . . . 337

Vermittelst und sein Anhang . . . . . . . . . 339

Seitens ............ . . . 343

Beziehungsweise ............ 346

Provinzialismen .......... . . 349

Fremdwörter ............ 351

Die Aküsprache .......... . . 379

Die Fachausdrücke der Sprachlehre . . . . . 386

Wort- und Sachverzeichnis ...... 388 